\title{
Identifying Patient- and Family-Centered Outcomes Relevant to Inpatient versus At- Home Management of Neutropenia in Children with Acute Myeloid Leukemia
}

\author{
Julia E. Szymczak, $\mathrm{PhD}^{1,2}$; Kelly D. Getz, PhD, $\mathrm{MPH}^{3,4}$; Rachel Madding, $\mathrm{BA}^{3,4}$; Brian
} Fisher, DO, MSCE ${ }^{2,4}$; Elizabeth Raetz, MD ${ }^{6}$; Nobuko Hijiya, $\mathrm{MD}^{7,8}$; Maria M. Gramatges, $\mathrm{MD}, \mathrm{PhD}^{9}$; Meret Henry, MD ${ }^{10}$; Amir Mian, $\mathrm{MD}^{11}$; Staci D. Arnold, MD, $\mathrm{MPH}^{12}$; Catherine Aftandilian, $\mathrm{MD}^{13}$; Anderson B. Collier, $\mathrm{MD}^{14}$; and Richard Aplenc, $\mathrm{MD}, \mathrm{PhD}^{2,3,4}$

\footnotetext{
${ }^{1}$ Department of Biostatistics, Epidemiology and Informatics, University of Pennsylvania School of Medicine

${ }^{2}$ Center for Clinical Epidemiology and Biostatistics, University of Pennsylvania School of Medicine

${ }^{3}$ Division of Oncology, The Children's Hospital of Philadelphia

${ }^{4}$ Center for Pediatric Clinical Effectiveness, The Children's Hospital of Philadelphia

${ }^{5}$ Division of Infectious Diseases, The Children's Hospital of Philadelphia

${ }^{6}$ Department of Pediatrics and Huntsman Cancer Institute, University of Utah

${ }^{7}$ Department of Pediatrics, Northwestern University Feinberg School of Medicine

${ }^{8}$ Division of Pediatric Hematology Oncology, Ann \& Robert H. Lurie Children's Hospital of Chicago

${ }^{9}$ Texas Children's Cancer Center; The University of Texas MD Anderson Cancer Center

${ }^{10}$ Division of Hematology/Oncology, Children's Hospital of Michigan, Wayne State University

${ }^{11}$ Department of Pediatric Hematology-Oncology, Arkansas Children's Hospital

${ }^{12}$ Department of Pediatrics, Emory University

${ }^{13}$ Division of Pediatric Hematology/Oncology, Stanford University School of Medicine and Lucile Packard

Children's Hospital

${ }^{14}$ Department of Pediatrics, Division of Hematology/Oncology, University of Mississippi Medical Center
}

\section{Corresponding Author}

Julia E. Szymczak, PhD

Blockley Hall Room 708

423 Guardian Drive

Philadelphia, PA 19104-4302

(215) 898-1793

jszymcza@pennmedicine.upenn.edu

Word Count

Abstract - 100 words

Main Text-1491 words

\section{Number of Tables \\ 2 \\ Running Title}

Patient Centered Outcomes for Neutropenia Management

Keywords

patient-reported outcomes; neutropenia; acute myeloid leukemia; qualitative methodology

Abbreviation Key

This is the author manuscript accepted for publication and has undergone full peer review but has not been through the copyediting, typesetting, pagination and proofreading process, which may lead to differences between this version and the Version of Record. Please cite this article as doi: $10.1002 / \mathrm{pbc} .26927$.

This article is protected by copyright. All rights reserved. 


\begin{tabular}{|l|l|}
\hline AML & Acute Myeloid Leukemia \\
\hline ABSTRACT &
\end{tabular}

Efficacy of therapeutic strategies relative to patient- and family-centered outcomes in pediatric oncology must be assessed. We sought to identify outcomes important to children with acute myeloid leukemia (AML) and their families related to inpatient versus at-home management of neutropenia. We conducted qualitative interviews with 32 children $\geq 8$ years old and 54 parents. Analysis revealed the impact of neutropenia management strategy on siblings, parentanxiety, and child sleep quality as being outcomes of concern across respondents. These themes were used to inform the design of a questionnaire that is currently being used in a prospective, multi-institutional comparative effectiveness trial.

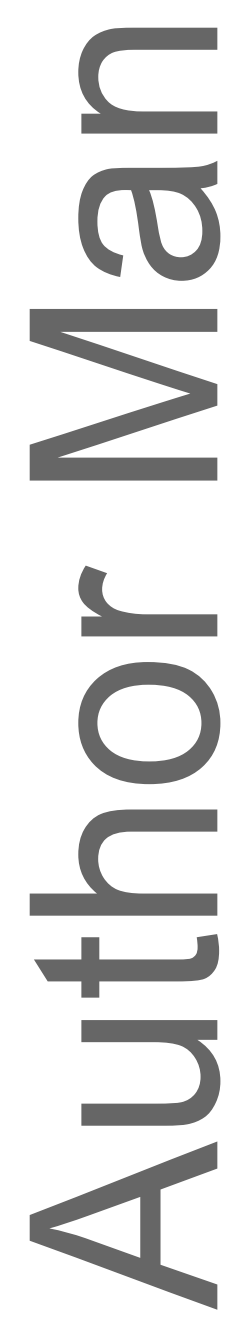




\section{INTRODUCTION}

The approach to management of neutropenia following chemotherapy among children with acute myeloid leukemia (AML) varies between treatment institutions. ${ }^{1,2}$ Some centers hospitalize children until neutropenia resolves, whereas others monitor patients in an outpatientsetting. Little data exist on the comparative effectiveness of these two strategies. ${ }^{3}$ In addition to objective assessment of clinical outcomes, such as infection, it is important to consider patient-and family-centered outcomes specific to each of these two strategies.

Safely tailoring care based on patient and family preference may increase satisfaction and minimize conflict with the care team. ${ }^{4}$ Research on preferences related to neutropenia management has demonstrated that many parents would prefer inpatient care if they were given a choice, but anticipate that their quality of life would be higher with at-home management. ${ }^{5-7}$ These studies were limited to the investigation of what parents anticipate they would experience, rather than actual experiences. Pediatric patient perceptions surrounding neutropenia management have to date not been investigated, which is a notable knowledge gap.

Our objective was to identify patient- and family-centered outcomes related to inpatient versus at-home management of neutropenia in children with AML and their families to be used in a prospective, multi-institutional comparative effectiveness trial. Our study was informed by a social-ecological framework for understanding coping and adaptation in childhood disease. ${ }^{8}$ A qualitative approach was selected in order to elicit in-depth narratives of the patient and family experience of the neutropenic period that contained detailed information about the ongoing, daily issues that the child and their family faced during neutropenia across the social contexts in which they are embedded. The purpose of this brief

This is the author manuscript accepted for publication and has undergone full peer review but has not been through the copyediting, typesetting, pagination and proofreading process, which may lead to differences between this version and the Version of Record. Please cite this article as doi: $10.1002 / \mathrm{pbc} .26927$.

This article is protected by copyright. All rights reserved. 
report is to describe the approach we used to identify a limited number of patient- and familycentered outcomes.

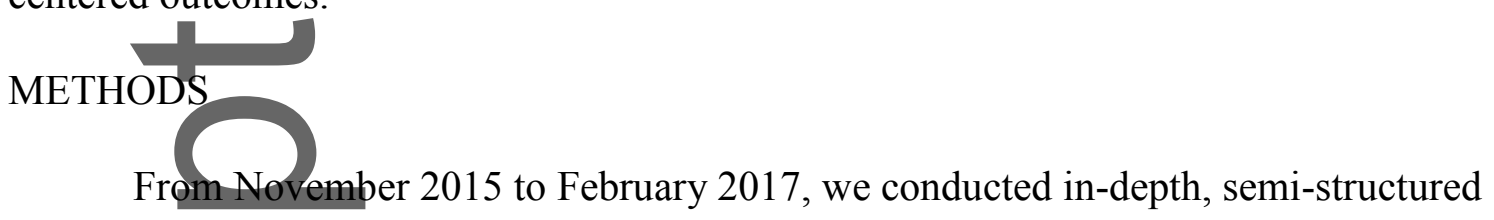
interviews with children and their families who completed AML chemotherapy at 1 of 9 children's hospitals across the United States. Five of these hospitals have implemented home management of neutropenia. We purposely sought interviews at institutions where neutropenia was either managed in the hospital or managed at home, in order to investigate variation in experience depending on management strategy. ${ }^{9}$ At each site, we recruited children diagnosed with AML and their parents. Children were eligible for inclusion if they were within 6-12 months of completion of the second course of chemotherapy or up to 3 years after completion of all frontline AML chemotherapy. We selected these time periods to ensure a reasonable sample size. We recruited 116 eligible individuals to participate in our study. There were 86 respondents, from 57 families with a child with AML enrolled in our study, for a response rate of $74.1 \%$.

The study protocol was approved by the Children's Hospital of Philadelphia institutional review board. Interviews were conducted by a trained interviewer in person during our study team's 1 week site visit to each children's hospital or over the telephone. The interview guide included open-ended questions on the patient and family experience of neutropenia (see-Supplementary Table S1). Parents and children were given the choice of separate intervieys or to participate in an interview together. Respondents were recruited until thematic saturation, the state where increasing sample size would no longer produce new insights, was achieved. ${ }^{10}$

Audio files were transcribed and uploaded to NVivo 11 qualitative data analysis software. ${ }^{11}$ Data were analyzed using a modified grounded theory approach in which 2 
analysts systematically identified themes and patterns in the text via open coding. ${ }^{12}$ All transcripts were read line-by-line and salient concepts were identified, defined and refined. Because the primary purpose of this qualitative investigation was to identify a limited number of patient and family centered outcomes related to the management of neutropenia that could be used in our prospective comparative effectiveness study, here we describe the 3 most common themes that emerged across respondents. For more detailed information about our methodology, see Supplementary Materials.

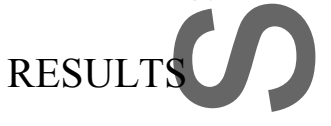

Respondent Characteristics

Of the 57 children in our study, 39 were cared for as inpatients while neutropenic and 18 were managed at home. We interviewed 54 parents (44 mothers, 8 fathers and 2 grandparents) and 32 children (Table 1). Twenty-one children decided to be interviewed separately from their parents. The mean age of the patient was 14.4 years (standard deviation, $6.54)$ and 27 of the patients (47\%) were male. Interviews ranged in length from 10-118 minutes, with a mean length of 39.6 minutes (standard deviation, 22.15).

\section{Patient- and Family-Centered Outcomes}

We identified 3 recurrent themes related to neutropenia management that are important to our respondents. First, in families with multiple children, both patients and parents reported substantial distress related to the impact of prolonged hospitalizations on siblings. Parents described emotional moments when children and their siblings were separated at the conclusion of a sibling's visit to the hospital (see Q1 in Table 2). Mothers of hospitalized children reported worrying about balancing the needs of multiple children (Q2). Children reported missing their siblings, friends and extended families (Q3).

Second, parents described feeling safer and less anxious in the hospital (Q4). The majority of parents who managed children at home expressed anxiety related to preventing 
infection, managing central line care (Q5), monitoring for fever, and their ability to transport their child to the hospital in a timely fashion in case of an emergency. Interestingly, among children treated inpatient, both parents and children reported feeling that the hospital served an important social function that mitigated anxiety - as a space where children could be themselves and did not need to manage the burden of explaining their illness to others (Q6, Q7).

Third, children treated inpatient reported significant sleep disturbances due to frequent interruptions for monitoring of vitals (Q8) as well as excessive light and uncomfortable beds (Q9). Some teenagers also described purposefully engaging in dysfunctional sleep patterns to avoid interactions with the medical team during the day (Q10).

We examined whether there was variation in these themes by respondent characteristics, including time out of therapy, race/ethnicity, socioeconomic status and family structure. With the exception of only-child families (where impact on siblings was not identified), we found these 3 outcomes to be important across respondents.

\section{DISCUSSION}

An in-depth qualitative investigation of the experiences of children with AML and their families revealed a number of important patient- and family-centered outcomes related to neutropenia management including impact of the hospitalization on siblings, parent anxiety and patient sleep quality. Our respondents identified these three issues as key challenges during this period of therapy. These data expand on what is already known about parentanticipated preferences related to neutropenia management by demonstrating additional factors that influence parent and child quality of life.

Using an open-ended qualitative design allowed for the discovery of unanticipated insights related to the subjective experience of children and families. For example, while it is 
not surprising to learn that parents who care for a neutropenic child at home experience anxiety surrounding preventing infection and perceive the hospital to be safer, ${ }^{7}$ it is surprising that they describe social advantages to their child's hospitalization. This experience is likely mitigated by the resources of the hospital to support children's educational and psychosocial needs.

Pediatric patients are embedded in the context of a family, whose members are also substantially impacted by the burden of serious illness. ${ }^{13}$ A child's experience of critical illness is profoundly shaped by their interactions with their parents and siblings. In addition, parents play a major role in absorbing the burden of treatment on behalf of their children. ${ }^{14}$ Therefore, it is critical to better understand parent preferences. The results of our study stress the importance of incorporating patient- and family-centered outcomes in determining the oomparative effectiveness of strategies for prolonged medical management. Our findings confirm the results of previous research that highlights the importance of minimizing sleep disruptions during prolonged hospitalizations ${ }^{15}$ and the need to develop supportive interventions to mitigate the negative impact that cancer therapy can have on the entire family unit. ${ }^{16,17}$

Our study has several limitations. First, although we included respondents from a range of pediatric hospitals, the utilization of a qualitative design limits the generalizability of our findings. Second, it is possible that our respondents possessed systematically different characteristics that influenced their willingness to participate when compared with those who declined to participate. We did not gather information about those who declined to participate so we cannot assess selection bias. Further, we cannot exclude unmeasured differences affecting participation decisions related to specific positive or negative experiences during treatment. 
Despite these limitations, our findings reveal patient- and family-centered outcomes that permit a more comprehensive understanding of the comparative difference in at home versus inpatient management of neutropenia. The themes described here have been used by our research team to design a structured questionnaire for a prospective multi-institutional trial. In addition to more traditional clinical outcomes, like bacteremia, we have incorporated measures of child sleep disruption, impact of siblings and parent anxiety into our trial. This enables a quantitative comparison of patient- and family-centered outcomes among neutropenic pediatric AML patients managed in the hospital versus at home.

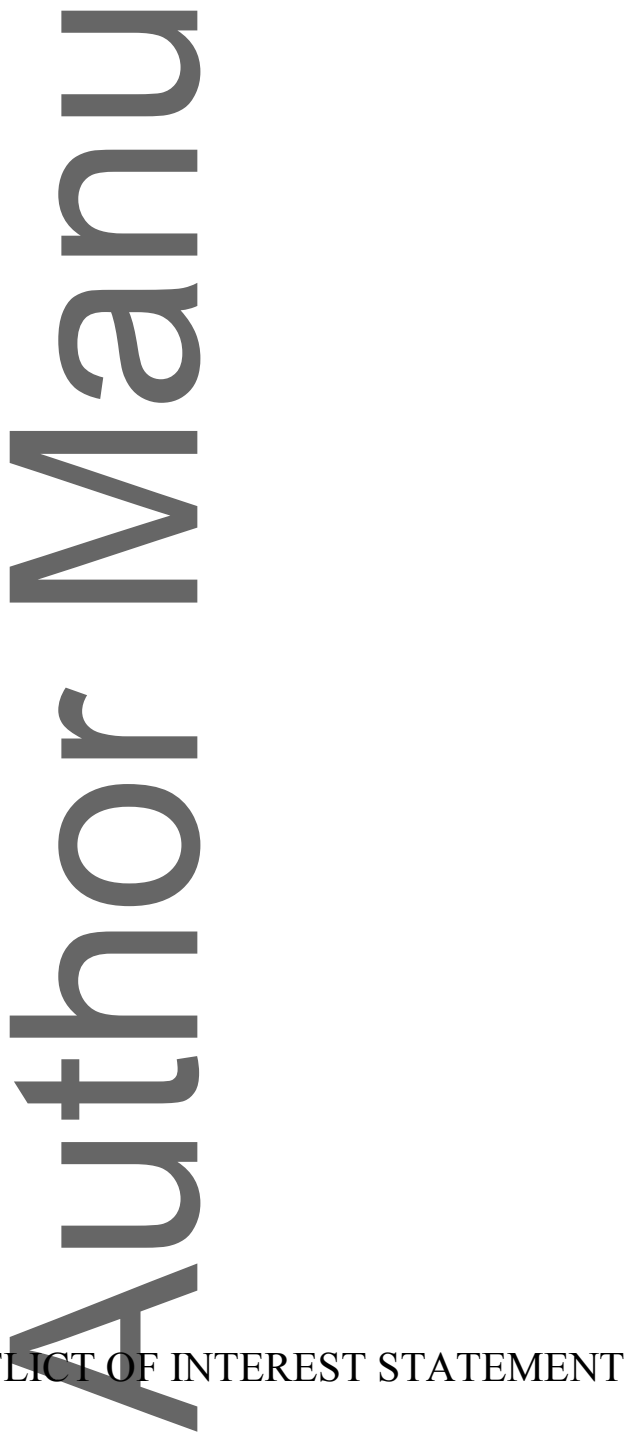

The authors of this manuscript have no relevant conflicts of interest to disclose. 


\section{ACKNOWLEDGEMENTS}

We gratefully acknowledge the support of Monica Newmark, Kathryn Sparks, Yolanda Santiago, Andria Stevens, Caitlin Herring, Carol Oldridge, Deveree Partridge, Rachel Lowery and Katie David for their hard work in recruiting patients. This study was supported by the Patient Centered Outcomes Research Institute (PCORI).

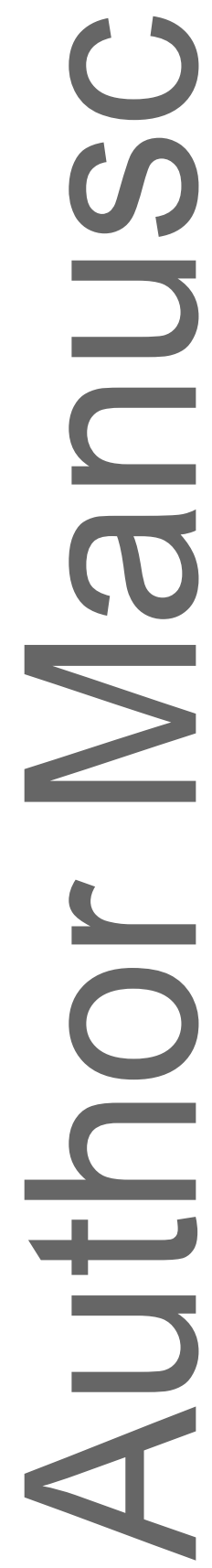




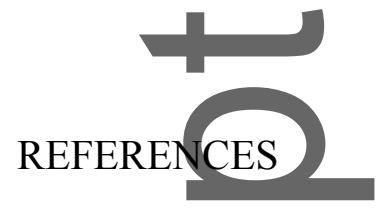

1. Lehrnbecher T, Ethier MC, Zaoutis T, et al. International variations in infection supportive care practices for paediatric patients with acute myeloid leukaemia. $\mathrm{Br} J$ Haematol. 2009;147(1):125-128.

2. Sung L, Aplenc R, Alonzo TA, Gerbing RB, Lehrnbecher T, Gamis AS. Effectiveness of supportive care measures to reduce infections in pediatric AML: a report from the Children's Oncology Group. Blood. 2013;121(18):3573-3577.

3. Lehrnbecher T, Phillips R, Alexander S, et al. Guideline for the management of fever and neutropenia in children with cancer and/or undergoing hematopoietic stem-cell transplantation. J Clin Oncol. 2012;30(35):4427-4438.

4. Sung L, Regier DA. Decision making in pediatric oncology: evaluation and incorporation of patient and parent preferences. Pediatr Blood Cancer. 2013;60(4):558-563.

5. Cheng S, Teuffel O, Ethier MC, et al. Health-related quality of life anticipated with different management strategies for paediatric febrile neutropaenia. Br J Cancer. $2011 ; 105(5): 606-611$.

6. Sung L, Feldman BM, Schwamborn G, et al. Inpatient versus outpatient management of low-risk pediatric febrile neutropenia: measuring parents' and healthcare professionals' preferences. J Clin Oncol. 2004;22(19):3922-3929.

7. Diorio C,Martino J, Boydell KM, et al. Parental perspectives on inpatient versus outpatient management of pediatric febrile neutropenia. J Pediatr Oncol Nurs. $2011 ; 28(6): 355-362$. 
8. Kazak AE. Families of chronically ill children: a systems and social-ecological model of adaptation and challenge. J Consult Clin Psychol. 1989;57(1):25-30.

9. Mites MB, Huberman AM, Saldana J. Qualitative Data Analysis: A Methods Sourcebook. Thousand Oaks, CA: Sage; 2014.

10. Guest G, Bruce A, Johnson L. How many interviews are enough? An experiment with data saturation and variability. Field Methods. 2006;18(1):23.

11. NVivo qualitative data analysis Software [computer program]. Version 11: QSR International Pty Ltd.; 2016.

12. Charmaz K. Constructing Grounded Theory: A Practical Guide Through Qualitative Analysis. Thousand Oaks, CA: Sage; 2006.

13. Shudy M, de Almeida ML, Ly S, et al. Impact of pediatric critical illness and injury on families: a systematic literature review. Pediatrics. 2006;118 Suppl 3:S203-218.

14. Forrest CB, Silber JH. Concept and measurement of pediatric value. Acad Pediatr. 2014;14(-5 Suppl):S33-38.

15. Linder LA, Christian BJ. Nighttime sleep disruptions, the hospital care environment, and symptoms in elementary school-age children with cancer. Oncol Nurs Forum. $2012 ; 39(6): 553-561$.

16. Rosenberg AR, Dussel V, Kang T, et al. Psychological distress in parents of children with advanced cancer. JAMA Pediatr. 2013;167(6):537-543.

17. Alderfer MA, Long KA, Lown EA, et al. Psychosocial adjustment of siblings of children yith cancer: a systematic review. Psychooncology. 2010;19(8):789-805.

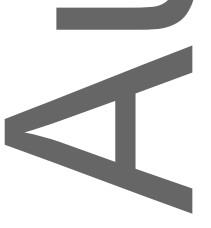


Methodological Appendix

Supplementary Table S1: Sample Interview Questions

Table 1

Characteristics of Respondents

$n=86$ respondents (from 57 families)

\begin{tabular}{|c|c|}
\hline 10 & $n$ \\
\hline \multicolumn{2}{|l|}{ Respondent } \\
\hline Mother & 44 \\
\hline Father & 8 \\
\hline Child ( $\geq 8$ years old) & 32 \\
\hline Grandparent & 2 \\
\hline \multicolumn{2}{|l|}{ Child Age } \\
\hline $0-5$ & 17 \\
\hline $6-10$ & 5 \\
\hline $11-15$ & 13 \\
\hline $16-21$ & 22 \\
\hline \multicolumn{2}{|l|}{ Child Race/Ethnicity } \\
\hline Asian & 3 \\
\hline Black or African American & 12 \\
\hline White & 42 \\
\hline Hispanic, Latino, Spanish & 4 \\
\hline \multicolumn{2}{|l|}{ Parent/Grandparent Education Level } \\
\hline Less than High School & 3 \\
\hline High School/GED & 9 \\
\hline Some College & 18 \\
\hline Bachelor's Degree & 20 \\
\hline Advanced Degree & 4 \\
\hline \multicolumn{2}{|l|}{ Respondent Region of Residence } \\
\hline Northeast & 32 \\
\hline South & 25 \\
\hline Midwest & 14 \\
\hline West & 15 \\
\hline \multicolumn{2}{|l|}{ Point in Treatment } \\
\hline $\begin{array}{l}\text { Within 6-12 months of completion of the } \\
\text { second course of chemotherapy }\end{array}$ & 33 \\
\hline Up to 3 years after completion of all therapy & 24 \\
\hline \multicolumn{2}{|l|}{ Number of Siblings } \\
\hline 0 & 4 \\
\hline 1 & 16 \\
\hline 2 & 21 \\
\hline$\geq 3$ & 16 \\
\hline
\end{tabular}

This article is protected by copyright. All rights reserved. 
Table 2

Themes Identified and Illustrative Quotations

\begin{tabular}{|c|c|c|}
\hline Theme & $\begin{array}{l}\text { Number (\%) of } \\
\text { Respondents } \\
\text { Who } \\
\text { Mentioned } \\
\text { Theme } \\
\end{array}$ & Illustrative Quotations \\
\hline $\begin{array}{l}\text { Impact of } \\
\text { prolonged } \\
\text { hospitalizat } \\
\text { on siblings }\end{array}$ & $63(73.2 \%)$ & $\begin{array}{l}\text { Q1."Our room faced the parking lot and sometimes oftentimes } \\
\text { with siblings you think, do they even love each other? Like you } \\
\text { wonder, they fight and tease and bug. But then it was interesting. } \\
\text { When they would leave, we could see across the parking lot and } \\
\text { you could just see the sadness on all their faces. It was so hard. } \\
\text { He would cry. We all cried and it was hard to watch them go. It } \\
\text { was heartbreaking. And I couldn't be there for my other kids } \\
\text { because I was in the hospital with him.” Mother (inpatient) } \\
\text { Q2. "So I was like I gotta spend some time with my other child, } \\
\text { my son. I miss him, I know he misses me and us being away } \\
\text { from each other for all that time, you know, is not good. So my } \\
\text { grandmother had came up here and I had stayed all day and it } \\
\text { was time where I needed to come home and she didn't want me } \\
\text { to leave. She hollered, screamed, kicked, everything. The nurses } \\
\text { tried to calm her down. I talked to her on the phone on my way } \\
\text { home and talked her down." Mother (inpatient) } \\
\text { Q3. "I felt pretty isolated 'cause they wouldn't let any of my } \\
\text { family and friends come in more than two at a time and my } \\
\text { visitors had to wear a mask. So I felt pretty alone 'cause I felt } \\
\text { like everyone was trying to just keep a bubble around me. And I } \\
\text { think that's when I really wanted to go home the most because I } \\
\text { never was able to see barely anyone." Adolescent (inpatient) }\end{array}$ \\
\hline Parent any & $74(86 \%)$ & $\begin{array}{l}\text { Q4."I would have much rather been in the hospital the whole } \\
\text { time. I loved it. I loved it because it was stressless. It's better } \\
\text { than being home 'cause when I was home I would always shiver } \\
\text { - I was so scared. But when I was there, I never shivered. When I } \\
\text { was home I didn't get any help and I couldn't sleep 'cause I was } \\
\text { always watching her. That's why I liked going to the hospital } \\
\text { more. I could sleep in the hospital. And that was on a couch. I'd } \\
\text { find that room to be like a castle. Like, I could get some rest. And } \\
\text { when they said it was time to go home, I'd be happy a little } \\
\text { 'cause of my other kids but at the same time, from inside I'm } \\
\text { not." Mother (home management) } \\
\text { Q5."The first time I took him home during our } 10 \text { day break it } \\
\text { scared me to death, because I was like, now I have to be the one } \\
\text { monitoring him and making sure he doesn't get sick...It kinda } \\
\text { scared me...I was like 'oh dear, ok.' So, you have to flush the } \\
\text { line, because if not it could get clots into his heart... But it really } \\
\text { made me nervous at first because I was like, ok, I hope I'm } \\
\text { pushing this in there right and making sure I did everything I } \\
\text { could.” Mother (inpatient) }\end{array}$ \\
\hline
\end{tabular}




\begin{tabular}{|c|c|}
\hline$\square$ & $\begin{array}{l}\text { Q6. "If I didn't have any other kids, if it would just have been her } \\
\text { I would have preferred to have been in a place where she was } \\
\text { inpatient all the time. The people on the 17th floor were really } \\
\text { like a family to us. When we left I was always kind of like, } \\
\text { "We're leaving behind family." When we would leave, of course } \\
\text { I would be ready to get the f*** out of there but, at the same } \\
\text { time, you're like, "We're leaving the people who are well- } \\
\text { equipped to help her." So if she was my only child I would have } \\
\text { preferred to have been at a facility that kept us the whole time } \\
\text { because I feel like that anxiety at ANC of zero would not exist } \\
\text { because I would have been surrounded by people who would } \\
\text { have already been looking for the signs that we at home were } \\
\text { looking for and could do something about it right away." Mother } \\
\text { (home management) } \\
\text { Q7. "Mother: Going to the hospital, as long as she knew she } \\
\text { would eventually come home, going to the hospital was like an } \\
\text { extension of the family. It was doctors and nurses that knew what } \\
\text { she was going through. She didn't have to explain anything. She } \\
\text { could be herself and they knew that - they knew everything she } \\
\text { was going through. So she knew she had to go to the hospital, but } \\
\text { it could've been worse. She was going to be with people who } \\
\text { generally cared about her, loved her. } \\
\text { Child: I had doctors that picked out nail polish for me, the nurses } \\
\text { would joke around with me, color with me. } \\
\text { Mother: She knew that when she went to the hospital, she wasn't } \\
\text { so isolated, even though sometimes she was on isolation." } \\
13 \text { year old and Mother (home management) }\end{array}$ \\
\hline $\begin{array}{l}\text { Quality of } \\
\text { child's sleep }\end{array}$ & $\begin{array}{l}\text { Q8."Okay, the biggest difference between staying at the hospital } \\
\text { and staying at home -you actually get sleep at home. Like at the } \\
\text { hospital it's once every four hours they come in and they check } \\
\text { all your vitals and stuff so you're waking up for that. I mean, it's } \\
\text { just really like, they bug the crap out of you. The nurses they're } \\
\text { coming in all the time and like the lights in the hallway never go } \\
\text { off. I think I got better faster at home when I could sleep." } 17 \\
\text { year old (home management) } \\
\text { Q9."The hospital beds, I didn't like 'em at all. They didn't feel } \\
\text { right to me. When I would wake up I would sit in a chair. I } \\
\text { wasn't in the bed at all during the day unless I was taking a } \\
\text { nap...If I could get comfortable in the bed I slept well, it was just } \\
\text { that getting to the point where I could actually sleep, I guess, was } \\
\text { hard." } 15 \text { year old (inpatient) } \\
\text { Q10. "And then towards the nighttime, that's when I would try to } \\
\text { stay awake because doctors don't really want to wake you up } \\
\text { when you're sleeping. So I would sleep during the day to kind of } \\
\text { try to avoid them. And then during the night I'd say up as late as } \\
\text { 5:00 in the morning because it was so quiet." } 12 \text { year old } \\
\text { (inpatient) }\end{array}$ \\
\hline
\end{tabular}

This article is protected by copyright. All rights reserved. 